\title{
articles
}

\section{The use of restraints in psychiatric patients}

M Y H Moosa, MMed (Psych), FCPsych, MCFP

F Y Jeenah, MMed (Psych), FCPsych

University of the Witwatersrand, Johannesburg

Restraints are usually used for the protection of patients and others when medication and verbal therapies are insufficient to control potentially violent patients. Many fear the abuse of restraints as well as their psychological, physical and emotional consequences.

In South Africa, according to the Mental Health Care Act No. 17 of 2002, the use of restraints is permissible but subject to certain regulations. Restraint may not be used any longer than is necessary to prevent serious bodily harm to the patient or others. When restraint has the desired effect of settling the patient's behaviour to the point where control is regained, its further imposition is illegal.

Restraints may be classified into three main categories: (i) environmental restraints; (ii) physical restraints; and (iii) chemical restraints. There is much debate over what types of restraint are superior. There may be differences in cost, risk of serious staff injury, requirements of staff time for monitoring and implementation, and impacts on staff and patient attitudes.

It is hoped that the use of environmental and physical restraint will be rendered obsolete by advances in the field of psychiatry such psychopharmacology and the therapeutic milieu. In order to reach this goal more research needs to be done on restraint practices across a wide range of psychiatric treatment settings.

Some people view restraint of psychiatric patients as a violation of basic human rights, others as a necessity for the control of violence, and yet others as a therapeutic modality. Throughout history the practice of restraint has been associated with punishment, custodial care, institutional abuse and neglect. Restraint was not discovered by scientific research. Rather, its origins go back to the natural response of primitive societies to the danger posed by a mentally deranged member.' These individuals were banished, tied down or caged. Fortunately reform, moral progress and humanitarianism have decreased these practices. Potentially dangerous mentally ill patients are now admitted to hospitals.
One of the strongest justifications for the use of restraints in hospitals is the protection of the patient, others or both. Often medication and verbal therapies are insufficient to control potentially dangerous patients. ${ }^{2}$ This and the possible beneficial therapeutic effects of restraints are some strong justifications for their use. In addition, restraint of violent patients allows the staff in psychiatric hospitals to feel safe enough to perform basic psychotherapeutic tasks that often serve to prevent or avoid further violence.

\section{Ethics of restraints}

Many fear the abuse of restraints and possible psychological, physical and emotional consequences. Restraints may involve physical and psychological risks, ${ }^{3}$ produce negative reactions in patients and staff, ${ }^{4}$ be used as punishment to patients, ${ }^{5}$ or be used more frequently than should be necessary due to staffing shortages. ${ }^{6}$ Restraint procedures not only represent a significant infringement of an individual's right to autonomy and selfdetermination 7 but may be associated with significant morbidity and mortality. Attitudes of patients and staff toward restraints differ greatly. Patients' attitudes are generally negative, whereas staff tend to believe that seclusion benefits patients and preserves the unit's smooth functioning. ${ }^{8}$

Restraint of psychiatric patients raises social and moral issues such as the importance of freedom and the rights of the individual as opposed to the group. ${ }^{9}$ Systematic studies of the effectiveness of restraints are lacking, as is research on events transpiring during seclusion. ${ }^{10-12}$ The incidence and duration of restraint differ widely across institutions. Differences may be better explained by hospital factors such as location, staff attitudes and treatment philosophy than by patient characteristics. ${ }^{13}$

\section{Definition}

'To restrain' means 'to place under control when necessary to prevent serious bodily harm to the patient or to another person, by the minimal use of such force (mechanical means or chemicals) as is reasonable having regard to the physical and mental condition of the patient'. ${ }^{14}$ The word 'serious' implies that the risk to the patient or others should not be slight, negligible or frivolous. There must be an apparent risk of real harm to the patient or others before restraint is employed. 


\section{Legislative framework}

According to the Mental Health Care Act (MCHA) No. 17 of $2002^{15}$ the use of restraints is permissible, but the following regulations apply: ${ }^{16}$

1. Mechanical means of restraint may not be used during transfer of a mental health care user or within a health establishment unless pharmacological or other means of calming, physical means of restraint or seclusion of the user are inadequate to ensure that the user does not harm him- or herself or others.

2. Where mechanical means of restraint are required in order to administer pharmacological treatment, such means should be applied for as short a period, depending on the condition of the mental health care user concerned, as is necessary to effect the treatment.

3. While the mental health care user is under restraint, he or she must be subject to observation at least every 30 minutes and such observations should be recorded in the clinical notes.

4. Whenever mechanical means of restraint is utilised:

(a) a register kept for that purpose must be signed and completed by the relevant medical practitioner;

(b) the form of mechanical means of restraint, the time period used, the times when the mental health care user was observed and the reason for administering such means of restraint must be outlined by the medical practitioner in the register contemplated in paragraph (a); and

(c) the head of the health establishment concerned must receive a report on a daily basis that indicates all incidents involving the use of mechanical means of restraint.

5. A transcript of the register contemplated in sub-regulation 4 must be submitted by the health establishment concerned to the Review Board on a quarterly basis as form MHCA 48 of the Annexure.

6. Mechanical means of restraint may not be used as punishment.

Chapter 37 of the $\mathrm{MHCA}^{16}$ on seclusion states that:

1. (a) A mental health care user may not be secluded as a punishment and seclusion may only be used to contain severely disturbed behaviour, which is likely to cause harm to others.

(b) Seclusion may not be used as a punishment.
2. While a mental health care user is secluded, he or she must be subject to observation at least every 30 minutes and that observation should be recorded in the clinical notes.

3. Whenever seclusion is utilised:

(a) a register, signed by a medical practitioner, must be completed;

(b) the time period over which the mental health care user concerned needed to be secluded and the reason for secluding that mental health care user must be outlined and the seclusion must be outlined in the relevant register by the medical practitioner; and

(c) the head of the health establishment concerned must receive a report indicating all incidents of seclusion on a daily basis.

4. A transcript of the register referred to above must be submitted to the Review Board by the health establishment concerned on a quarterly basis in the form of form MHCA 48 of the Annexure.

Interpretation of these regulations in the MHCA implies that restraints should not be used any longer than is necessary to prevent serious bodily harm to the patient or others. When restraint has the desired effect of settling the patient's behaviour to the point where control is regained, its further imposition is illegal. The words 'when necessary' mean that the imposition of 'force, mechanical means or chemicals' be used as a necessary last resort. Where a less intrusive means of therapeutic intervention could prevent serious bodily harm and the situation affords an opportunity for employing it, restraint is unwarranted. Further, the Act compels facilities to use the most 'minimal' form of restraint when such action is required.

\section{Classification of restraints}

Restraints may be classified into three main categories:

1. Environmental restraints, e.g. barriers to free personal movement that confine patients to specific areas, such as seclusion rooms.

2. Physical restraints, e.g. physical appliances that inhibit free physical movement and cannot be removed by the person to whom they are applied, such as jacket or hand restraints. The use of holding may provide body contact between a patient and one or more staff members. This type of restraint may seem more humane than the other types of restraint; however, there are limits to this type of restraint. For example, when a patient is in a violent state, physical restraining by others may be inflammatory. Conversely, when a patient is placed in a seclusion room, it 
has been demonstrated that a calming process begins. This is attributed to the huge reduction in stimulation that comes from being secluded. ${ }^{17}$ In addition, physical holding for every patient would require an exorbitant and impractical number of staff.

3. Chemical restraints, e.g. pharmaceuticals that are prescribed for the main purpose of altering or inhibiting specific behaviour, such as aggression. Chemical restraint is administered by a physician who must be adequately knowledgeable about the circumstances. However, in many jurisdictions chemical restraint may be used in an emergency in the absence of specific permission. There is always a risk from any major tranquilliser. However, self-mutilating behaviour and persistent violent physical struggling against mechanical restraints with the risk of exhaustion may require chemical restraint.

There is much debate as to what types of restraint are superior to others. There may be differences in cost, risk of serious staff injury, requirements of staff time to monitor and implement, and impact on staff and patient attitudes. The merits of one procedure may vary depending on variables such as patient and staff composition, type of ward and ward atmosphere. The type of restraint or seclusion used should be determined by the characteristics of the patient and what is in his or her best interests (e.g. psychiatric diagnosis, strengths, family history), and restraint should be used on the basis of the patient's clinical status and not general protocols or staff preferences.

The patient should be given the chance to choose appropriate control measures, even if he or she is of questionable competence. For example, it has been shown that adult patients overwhelmingly prefer seclusion to physical restraints. ${ }^{18} \mathrm{~A}$ patient in a seclusion room can move around if he wants to, whereas a patient in restraints can do nothing. Also a patient in restraints suffers the physical pain of forced immobility.

\section{Seclusion}

There is evidence that seclusion procedures are of therapeutic value when properly applied. Without an understanding of the purpose and therapeutic value of seclusion, it is more likely to be implemented poorly, to the detriment of patients and the morale of the staff who care for them..${ }^{19}$ It has been recognised by physicians that the regular imposition of predictable seclusion following episodes of undesirable loss of control has the observable effect of increasing the patient's self-control. ${ }^{20}$

However, there are many factors involved in making the seclusion process as therapeutic as possible. The policies must be defined, conducted in a consistent manner, explained to the patient, administered by well-trained professional and humanitarian staff and supervised by trained staff, and the space must be safe, attractive and soothing. The use of seclusion for children differs from that in adults, being more frequent and for briefer periods in the case of children.

The guidelines for determining when seclusion should be used include: (i) to prevent imminent harm to the patient or other persons when other means of control are not effective or appropriate; (ii) to prevent serious disruption of the treatment programme or significant damage to the physical environment; (iii) to assist in treatment as part of ongoing behaviour therapy; (iv) to decrease the stimulation a patient receives (pertaining solely to seclusion); and $(v)$ to comply with a patient's request. ${ }^{21}$

\section{Towards a restraint-free environment}

The following 'best practices' may assist facilities in moving towards a restraint-free environment: 22.28

1. Timely and comprehensive assessments of patients should be carried out to identify persons at risk, including complete biopsychosocial evaluations, detailed past psychiatric history and careful physical examination. The initial assessment should determine whether restraint is contraindicated or must be used with caution.

2. The core competencies of clinical staff should be continuously monitored and evaluated. These competencies to include early recognition of signs/symptoms of incipient crisis, conflict resolution, de-escalation techniques, crisis intervention and management, supportive psychotherapy, critical incident stress debriefing, and psychoeducation.

3. The use of restraints should be viewed as an extraordinary event and limited to recommended indications. Restraint requires a written order by the physician and its use should immediately be discontinued when less restrictive alternatives are feasible.

4. The plan of care of patients who have been restrained should reflect preferences and choices; provision of counselling, reassurance and support; explanation of the purpose for the use of restraint; explanation of specific behaviours prerequisite to discontinuation; and the process for reintegration into the programme milieu.

5. The basic dignity of patients who have been restrained should be protected, e.g. they should be provided with regular personal hygiene, bathroom, exercise, nutritional and fluid 
breaks. Patients who are restrained should be provided with a comfortable environment that supports and maintains human dignity, is safe, clean and attractive, has suitable lighting and ensures both auditory and visual privacy; natural light and exterior views should be used to enhance the environment and reinforce orientation; and ventilation should allow for acceptable levels of temperature and humidity and elimination of odours.

6. Psychiatric facilities should establish and standardise investigation policy and procedures related to complaints arising from restraint episodes. The complaint and investigation process must be effectively communicated to patients, family members and all hospital staff, easily accessible, subject to independent investigation consistent with the principles of due process, protect the complainant from reprisal, stipulate timeframes for completion of the investigation and decision making, and include avenues of appeal

\section{Conclusion}

It is the goal of medicine to give care and treatment without the infliction of pain, but pain unfortunately accompanies some treatments. Hippocrates stated 'primum, non nocere', I'first, do no harm'). Stabilising patients with dangerous behaviour requires the flexible use of these approaches, with the safety of the patient always first and foremost. If it becomes more difficult to provide a safe institutional environment for aggressive and violent patients, more psychiatric hospitals will close. These patients will be subjected to the ultimate in seclusion and restraint in the nontherapeutic environments of prisons and jails.

Guidelines should be developed in every psychiatric setting dealing with when to act, whether to administer restraint, and the duration of restraint. Legal and regulatory controls need to be implemented to monitor the use or misuse of restraints. This must be tempered by acknowledgement of the need for added resources that ensure adequate staffing and training in the appropriate use of these procedures to prevent violence.

It is to be hoped that the use of physical and environmental restraints will be rendered obsolete by advances in the field of psychiatry such as the use of psychopharmacology and the therapeutic milieu. In order to reach this goal more research needs to be done on restraint practices across a wide range of psychiatric treatment settings.

\section{References}

1. Westermeyer J, Kroll J. Violence and mental illness in a peasant society: Characteristics of violent behaviors and 'folk' use of restraints. Br I Psychiatry 1978 133: 529-541

2. Telintelo $S$, Kuhlman TL, Winget $C$. A study of the use of restraint in a psychiatric emergency room. Hospital and Community Psychiatry 1983; 34: 164-165.

3. Nelson SH, McKinney A, Ludwig K, et al. An unusual death of a patient in seclusion. Hospital and Community Psychiatry 1983; 34: 259.

4. Binder RL, McCoy SM. A study of patients' attitudes toward placement in seclusion. Hospital and Community Psychiatry 1983; 34: 1052-1054

5. Binder RL. The use of seclusion on an inpatient crisis intervention unit. Hospital and Community Psychiatry 1979; 30: 266-269

6. Hay D, Cromwell R. Reducing the use of full-leather restraints on an acute adult inpatient ward. Hospital and Community Psychiatry 1980; 31 : 198-200.

7. Oldham J, Russakoff LM, Prusnofsky L. Seclusion: Patterns and millieu. J Nerv Ment Dis 1983: 171: 645-650

8. Brown JS, Tooke SK. On the seclusion of psychiatric patients. Soc Sci Med 1992 35(5): $711-721$

9. Saks ER. Mechanical restraints. Yale Law Journal 1986: 95: 1850.

10. Gerlock A, Solomons HC. Factors associated with the seclusion of psychiatric patients. Perspect Psychiatr Care 1983, 21: 46-53.

1 1. Brown JS, Tooke SK. On the seclusion of psychiatric patients. Soc Sci Med 1992; 35: $711-721$

12. Bush $A B$, Shore MF. Seclusion and restraint: a review of recent literature. Harv Rev Psychiatry 2000; 8: 261-270

13. Brown JS, Tooke SK. On the seclusion of psychiatric patients. Soc Sci Med 1992 35: $711-721$

14. Sailas EA, Wahlbeck K. Patient vs staff perceptions of restraints in hospitals. 2006 Spocksbrain http:// spocksbrain.Livejournal.Com/7562.html laccessed 9 August 2009).

15. Mental Health Care Act, No 17, 2002. Pretoria: Department of Health. 2004 http://www.info.gov.za/gazette/acts/2002 (accessed 9 August 2009)

16. Mental Health Care Act, No 17, 2002: Regulations. Pretoria: Department of Health. 2004. http:/ / www info gov za/gazette/acts/2002 laccessed 9 August 2009].

17. Gutheil T. Observations on the theoretical bases for seclusion of the psychiatric inpatient. Am J Psychiatry 1978; 135: 325-328

18. Soliday SM. A comparison of patient and staff attitudes toward seclusion. J Nerv Ment Dis 1985: 173: 284

19. Cotton NS. The developmental-clinical rationale for the use of seclusion in the psychiatric treatment of children. Am J Orthopsychiatry 1989; 59: 442

20. Gair DS, Bullard DM, Corwin $\amalg$. Residential treatment seclusion of children as a therapeutic ward practice. Am J Orthopsychiatry 1965; 35: 251-252

21. Gutheil TG, Tardiff K. Indications and contraindications for seclusion and restraint. In: Tardiff K, ed. The Psychiatric Uses of Seclusion and Restraint. Washington, DC: American Psychiatric Press, 1984: 11-17.

22. Visalli $H, M c N a s s e r ~ G$, Lohnstone L, et al. Reducing high-risk interventions for managing aggression in psychiatric settings. J Nurs Care Qual 2000; 11:54-61.

23. Bower FL, McCullough CS. Restraint use in acute care settings. J Nurs Adm 2000 30: $592-598$

24. Dickey R. Assessing inmates for risk of future violence. Canadian Psychological Association Bulletin 2000: 32: 168-170.

25. Guebaly N, Atkinson MJ. Access to psychiatrists' care. Canadian Psychological Association Bulletin 2001; 33: 9-12.

26. Kates N, Adsett A, Bellissimo T, et al. The Hamilton psychiatric network: the evolution of an integrated network of psychiatric services. Can J Psychiatry 1993; 38: 31 5318.

27. Soliman AE, Reza H. Risk factors and correlates of violence among acutely ill adult psychiatric inpatients. Psychiatr Serv 200 1; 52: 75-80

28. Hancock CK, Buster PA, Oliver MS, et al. Restraint reduction in acute care. J Nurs Adm 2001:31: 74-77. 